\title{
БИОХИМИЧЕСКИЕ МАРКЕРЫ В ГЕНЕТИЧЕСКИХ ИССЛЕДОВАНИЯХ КУЛЬТУРНЫХ РАСТЕНИЙ: ПРИМЕНИМОСТЬ И ОГРАНИЧЕНИЯ (обзор)
}

\section{Ю.В. ЧЕСНОКОВ}

На основе данных литературы и результатов собственных исследований рассмотрены возможности использования запасных белков семян растений, аллоферментов и изоферментов в качестве биохимических генетических маркеров. Показано, что их применение имеет значительный потенциал, так как позволяет отличать один генотип от другого в сравнительно короткие сроки, к тому же биохимические маркеры, как правило, ткане- и органоспецифичны. Обсуждаются преимущества этого класса генетических маркеров перед обычными морфологическими маркерами. Так, биохимические маркеры можно использовать на значительно большем числе экспериментальных объектов, чем морфологические. Для белковых маркеров обычно характерно большее соответствие между генотипом и фенотипом, к тому же путь реализации генетических различий в фенотипические для белковых маркеров значительно короче, чем для морфологических. Кроме того, к биохимическим генетическим маркерам относят и метаболиты (сахара, углеводы, вторичные метаболиты и др.), которые идентифицируют биохимически после выделения из органов или тканей исследуемого организма и очистки. Несмотря на то, что с момента описания биохимических маркеров прошло более полувека, физико-химические подходы к их выявлению и идентификации методически почти не изменились, что накладывает определенные ограничения на использование таких маркеров в генетических исследованиях. Показано, что полиморфизм белков, выявляемый одномерным электрофорезом, может быть подвержен как качественному, так и количественному изменению из-за воздействия на растения экологического стресса, обусловленного, например, недостатком элементов питания или сменой температуры воздуха. Необходимо учитывать возможность нарушения структуры и целостности анализируемых молекул в силу разных причин, в том числе из-за несоблюдения стандартных условий экстракции белков и полипептидов при выделении и очистке, а также при электрофоретическом разделении, что может приводить к появлению неспецифических электрофоретических спектров. Поскольку во всех живых организмах существует вырожденность генетического кода и не каждая замена аминокислоты приводит к изменению заряда молекулы (как и к существенному изменению молекулярной массы белка), всего 30 \% нуклеотидных замен могут вызывать белковый полиморфизм, выявляемый при электрофорезе. Только при строгом учете всех без исключения факторов, накладывающих методические, биологические и иные ограничения, и соблюдении установленных требований биохимические маркеры могут быть корректно и квалифицированно использованы в генетических исследованиях.

Ключевые слова: запасные белки семян, аллоферменты, изоферменты, полиморфизм, электрофоретические спектры, биохимические маркеры.

Начало поиска молекулярных маркеров для решения практических задач генетики и селекции растений приходится на 1960-е годы. ДНКтехнологии в то время еще отсутствовали, и ученые при оценке и изучении генетического разнообразия стали использовать полиморфизм белков. Маркеры, основанные на выявлении генного продукта или продукта его активности, для визуализации которых требуется биохимический анализ, получили название биохимических. К этому классу маркеров относятся не только разного рода белки (запасные, транспортные, строительные, различные ферменты и др.), но и метаболиты (сахара, углеводы, вторичные метаболиты и др.), которые идентифицируют биохимически после выделения из органов или тканей исследуемого организма и очистки. В качестве маркеров в основном используются запасные белки семян растений или ферменты. Метаболиты как маркеры не получило широкого распространения вследствие специфики их обнаружения, требующей дорогостоящего и подчас специального оборудования (спектрофотометры, жидкостные и газовыы анализаторы высокого и низкого давления, перегонные кубы и др.). Однако применение этой группы биохимических маркеров заключает 
в себе значительный потенциал, так как позволяет отличать один генотип от другого в сравнительно короткие сроки; к тому же метаболиты, как правило, ткане- и органоспецифичны. Даже несмотря на то, что все они, как правило, доминантны, метаболиты как биохимические маркеры с успехом применяются при анализе генетического разнообразия, сохраняемого в коллекциях генетических ресурсов растений (1-4).

К рассматриваемому классу маркеров условно относят и биохимические мутации (5). У их носителей также присутствуют специфические органические молекулы, которые обнаруживаются биохимическими методами, но поскольку проявление таких мутаций можно непосредственно наблюдать на растении (без применения каких-либо биохимических манипуляций), подобные мутантные формы правильнее ассоциировать с классом морфологических маркеров, выявляемых фенотипически. Мы придерживаемся правила, согласно которому не стоит применять дополнительные дорогостоящие манипуляции (биохимические или молекулярно-биологические) для установления факта различий между генотипами, если для этого достаточно простого внешнего описания фенотипа.

Значительный прорыв в использовании маркерного биохимического анализа, получившего развитие во второй половине 1960-х годов, связан в первую очередь с широким распространением метода электрофореза различных белков (в том числе и ферментов) в генетических исследованиях, выполнявшихся на разных объектах.

Различия белков по электрофоретической подвижности, обусловленные аллельными замещениями в структурной части гена, можно использовать при анализе изменений генотипического состава популяций так же, как морфологические различия, связанные с маркерными локусами. В то же время белковые маркеры, наряду с некоторыми недостатками, которые будут рассмотрены ниже, обладают рядом преимуществ перед обычными морфологическими (6). Во-первых, электрофоретические биохимические маркеры можно использовать на значительно большем числе экспериментальных объектов, чем морфологические. Для этого не требуется в течение длительного времени создавать коллекции маркерных мутантов, поскольку многочисленные белковые варианты относительно легко обнаружить в имеющемся экспериментальном материале. Во-вторых, для белковых маркеров обычно характерно большее соответствие между генотипом и фенотипом. Так, на монолокусном уровне гомозиготы и гетерозиготы различают, например, с помощью изоферментного анализа, тогда как морфологические мутации часто рецессивны, реже доминантны, поэтому отличить гетерозиготу от обеих гомозигот, как уже отмечалось, обычно не удается. В-третьих, путь реализации генетических различий в фенотипические для белковых маркеров значительно короче, чем для морфологических. Наконец, в-четвертых, при расщеплении гибрида число морфологически различимых фенотипических классов между маркерными формами определяется числом гетерозиготных маркерных локусов $(n)$ и при полном доминировании составляет $2^{n}$. В то же время при анализе электрофоретических различий (аллельных форм), особенно в потомстве отдаленных гибридов, иногда обнаруживаются генотипы с новыми компонентами в белковом спектре, не наблюдаемыми ни у родительских форм ( $\mathrm{P}_{1}$ или $\left.\mathrm{P}_{2}\right)$, ни в $\mathrm{F}_{1}$. Выщепляются также особи, у которых в спектре отсутствуют линии, характерные для обоих родителей и $\mathrm{F}_{1}(7)$. Таким образом, метод электрофореза позволяет выявлять рекомбинанты с качественно новыми спектрами белков, которые нельзя спрогнозировать, поскольку они образуются не в результате простого комбинирования линий 
спектров $\mathrm{P}_{1}, \mathrm{P}_{2}$ и $\mathrm{F}_{1}$.

Не влияя на качественный состав белков, определяемых структурными генами, модификаторы изменяют активность последних и тем самым - количественные соотношения белковых фракций. Учет этих соотношений, которые можно рассматривать как обычные количественные признаки, позволяет дать более полную характеристику генотипа. О важности последнего обстоятельства можно судить на основе данных, полученных в опытах на дрозофиле: интенсивный искусственный отбор на увеличение устойчивости мух к этанолу приводит к значительному изменению количественных соотношений фракций алкогольдегидрогеназы, не влияя на их качественный состав $(8,9)$. Авторы показали, что эти результаты связаны с изменениями в разных регуляторных локусах. Аналогичные изменения белкового спектра в пределах жизни одного поколения происходят при адаптивной перестройке метаболизма в ответ на стрессовые воздействия $(7,10)$.

Запасные белки семян растений, алло- и изоферменты. Методические подходы к изучению генетического разнообразия с использованием белков впервые были разработаны в 1960-1970-х годах и с того времени практически не изменились. Для обнаружения и описания биохимических маркеров, ассоциированных с белковым полиморфизмом, чаще всего выполняют электрофоретическое разделение белков в полиакриламидном геле (polyacrylamide gel electrophoresis, PAGE) с последующим окрашиванием. В основном для этих целей исследуют запасные белки семян растений или определяют активность каких-либо ферментов.

Совместное изучение белков семян растений как молекулярных маркеров, начатое в 1972-1973 годах учеными ВИР (Всесоюзный НИИ растениеводства им. Н.И. Вавилова) и ISTA (International Seed Testing Association, https://www.seedtest.org/en/home.html), заложило основы сортовой идентификации и селекционной регистрации по электрофоретической подвижности запасных белков семян. В 1980 году 19-й Конгресс ISTA peкомендовал эти приемы для семеноводства и семенного контроля, а в 1983 году их приняли в качестве стандартов идентификации сортов у пшеницы и ячменя (11). На основании анализа запасных белков семян успешно картировали ген Rrs 14, определяющий устойчивость ячменя к патогену Rhynchosporium secalis (12), а также построили генетические карты для Pinus pinaster (13-15). Тем не менее описанный подход не получил широкого распространения в международной практике, так как такие маркеры охватывают не все группы сцепления $(12,16)$. При молекулярно-генетической идентификации растительных генотипов этот дешевый и простой в исполнении экспресс-тест, как правило, применяется для оценки больших торговых и семеноводческих партий семян либо при изучении исходного материала в семеноводстве и в связи с некоторыми проблемами сохранения растительных генетических ресурсов. В первую очередь это связано с тем, что в соответствии с центральной догмой молекулярной биологии белки не являются прямым проявлением генов. «Посредником» между ДНК (основном носитель генетической информации) и белком (биохимический продукт экспрессии гена) выступает мРНК. Как и ДНК, она может подвергаться различного рода эндогенным (перестройки, сплайсинг, мутации и т.п.) и/или экзогенным (например, факторы внешней среды) воздействиям (17). Как следствие, возможны изменения в структуре и активности транслируемых белков, то есть белки не отвечают в полной мере требованиям, предъявляемым к генетическим маркерам (18), и это несколько ограничивает их использование в подобном качестве. 
Электрофоретический анализ аллоферментов с 1960-х годов успешно применялся на различных группах организмов - от бактерий до многих видов животных и растений (19). Аллоферменты использовали в физиологических, биохимических, генетических, селекционных исследованиях для решения разных задач - при изучении структуры популяций, полиплоидии, проведении гибридизации и анализе гибридов, в систематике и др. $(20,21)$. Аллоферментный анализ относительно прост и легок в исполнении. Как правило, для его проведения готовят гомогенат какой-либо ткани, а полученный экстракт фракционируют в полиакриламидном или крахмальном геле. При этом белки, находящиеся в этом экстракте, последовательно разделяются по зарядам и размерам. После электрофореза гель окрашивают в соответствии с активностью выявляемого фермента, добавляя субстрат и краситель. В результате окрашивания (в соответствии с миграционным положением ферментного белка в геле) образуется характерный паттерн. В зависимости от числа локусов, их состояния (гомо- или гетерозиготность) и конфигурации ферментной молекулы в нем может быть от одной до нескольких полос. Они могут быть полиморфными, а потому информативными при определении генных локусов и групп сцепления.

Для маркерного анализа также используют изоферменты. Так, в работах на томате их применяли при изучении генетического разнообразия $(22,23)$, для локализации хозяйственно важных генов (24), при мониторинге чистоты гибридных семян (25), выявлении интрогрессии генов и хромосом диких видов (26), для проведения пыльцевой селекции (27), а также при скрининге гаплоидных генотипов, регенерированных в культуре клеток и тканей in vitro (28). Однако существует несколько ограничений, не позволяющих широко использовать изоферменты в качестве молекулярных маркеров (29). Мы уже касались общих требований к молекулярным маркерам (18); дополнительные условия, выполнение которых строго обязательно (особенно при составлении молекулярно-генетических карт), это, во-первых, наличие достаточного числа маркерных локусов, равномерно расположенных в геноме на расстоянии друг от друга не более 1015 сM, во-вторых, маркерный локус должен быть полиморфным с таким расчетом, чтобы любое проводимое скрещивание выявляло расщепление по интересующему исследователя маркерному локусу (30). Именно двум этим требованиям, предъявляемым к молекулярным генетическим маркерам, не отвечают изоферменты. Кроме того, чисто техническим ограничением служит невозможность детектировать и количественно оценить активность ферментов из-за отсутствия соответствующих красителей (их существенно меньше, чем идентифицированных ферментов, причем меньше половины таких красителей пригодны для анализа изоферментов растений) (31).

Иногда термины «изоферменты» и «аллоферменты» заменяют один другим, что нельзя считать корректным. Изоферменты распознают и расщепляют одни и те же субстраты, но не обязательно представляют собой продукты одного и того же гена. Изоферменты могут быть активны в разных клетках, тканях и/или органеллах либо на различных стадиях развития организма. Вариантом изоферментов являются аллоферменты - продукты ортологичных генов. Из-за их аллельных различий аминокислотный состав аллоферментов не совпадает по одной или нескольким аминокислотам. В дальнейшем мы будем использовать термин изоферменты (с учетом описанных различий).

Разделение белков в полиакриламидном геле методом одномерного электрофореза. Белковые маркеры (наряду с несомнен- 
ными преимуществами, выгодно отличающими их от морфологических маркеров) имеют ряд ограничений. Прежде всего еще раз отметим, что белки не относятся к первичным носителям генетической информации и представляют собой продукты транскрипции и трансляции кодирующих их генов. Помимо этого, полиморфизм белков, выявляемый одномерным электрофорезом, может быть подвержен как качественному, так и количественному изменению из-за воздействия на растения экологического стресса, обусловленного, например, недостатком элементов питания, что описано у ячменя (32), гороха (33), нута (34), сои (35), других культур $(36,37)$ (рис. 1) или сменой температуры воздуха (рис. 2) (6).

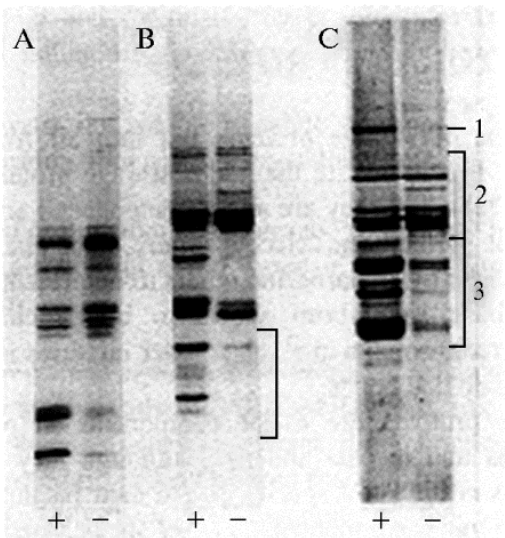

Рис. 1. Влияние недостатка серы («-») на формирование общих белков семян рапса (А), подсолнечника (В) и ячменя (С). Обращает на себя внимание присутствие фракций богатых серой низкомолекулярных белков (по-видимому, $2 \mathrm{~S}$ альбуминов) у рапса и подсолнечника и бедных серой гордеинов у ячменя (36).
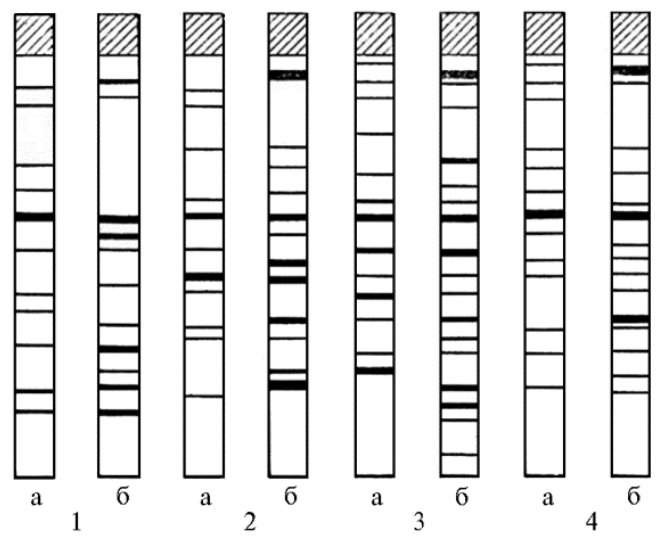

Рис. 2. Влияние температуры на электрофоретический спектр водорастворимых белков листьев у сеянцев разных видов рода Lycopersicon: $1-$ L. hirsutum var. glabratum, 2 - L. pimpinellifolium, $3-$ L. esculentum $(\mathrm{Mo500}) \times$ Solanum pinellii $\left(\mathrm{F}_{1}\right), 4-$ L. esculentum (сорт Тепличный 200); a $-25{ }^{\circ} \mathrm{C}$, $6-40{ }^{\circ} \mathrm{C}(6)$.

Необходимо учитывать возможность нарушения структуры и целостности анализируемых молекул в силу разных причин (18), в том числе из-за несоблюдения стандартных условий экстракции белков и полипептидов при выделении и очистке, а также при электрофоретическом разделении, что может приводить к появлению неспецифических электрофоретических спектров $(36,38-41)$. Вырожденность генетического кода также служит ограничением, поскольку значительно сужает спектр полиморфизма, выявляемого на уровне аминокислотных последовательностей по сравнению с полиморфизмом первичных нуклеотидных последовательностей, а значит и возможности анализа. Кроме того, известно, что всего лишь треть генома (или даже менее) кодирует и экспрессирует какие-либо белки. Следовательно, геномные изменения в некодирующей или регуляторной частях генов (а это более 70 \% генома) при исследовании белковых продуктов выпадают из поля зрения.

Тем не менее используемые в качестве биохимических генетических маркеров белки по-прежнему остаются привлекательным инструментом (11, 42-44). Причиной тому служат три основных преимущества запасных белков семян и изоферментов по сравнению с ДНК маркерами. Во-первых, это относительная простота белкового анализа с использованием сравнительно дешевых методов электрофореза. Во-вторых, у достаточно большого числа отдельных индивидуумов (генотипов) запасные белки или изоферменты могут быть проанализированы в течение сравнитель- 
но короткого времени. В-третьих, изоферменты, как и некоторые запасные белки семян, представляют собой кодоминантные маркеры, поскольку оба аллеля в диплоидном организме обычно достаточно ясно различимы и гетерозиготы могут быть отделены от гомозигот. Как правило, этого достаточно для установления частоты аллелей (в частности, в популяционной генетике). Однако позволяет ли разрешающая способность метода одномерного электрофоретического разделения белков выявить и верно оценить полиморфизм аминокислотных последовательностей, что составляет основу маркерного биохимического анализа?

Одномерный электрофорез белка, диссоциированного додецилсульфатом натрия (sodium dodecyl sulfate, SDS-PAGE), относится к наиболее часто используемым методам изучения полиморфизма растений с применением запасных белков семян в качестве маркеров $(11,12,43,44)$. Метод позволяет обнаруживать вариации молекулярной массы полипептида, возникающие в результате инделов (инсерций/делеций) в кодирующей области соответствующего гена, но он нечувствителен к изменениям заряда полипептида. Таким образом, применимость запасных белков семян в качестве молекулярных маркеров определяется частотой инделов и их размерами, которые должны быть достаточно велики для обнаружения вариаций молекулярной массы кодируемого полипептида. Проблема усугубляется гетерогенностью полипептидов запасных белков, сформировавшейся в результате макроэволюции порядков, семейств и родов растений. Иными словами, в задачу исследования внутривидового полиморфизма запасного белка с помощью SDS-PAGE должно входить описание модификаций молекулярной массы каждого из полипептидов, образовавшихся в процессе макроэволюционных событий.

Следовательно, внутривидовой полиморфизм запасного белка может быть описан только в том случае, если известны эволюционные взаимоотношения между образующими его полипептидами, по крайней мере на уровне семейств и родов растений. Так, в одной из работ (44) методом одномерного денатурирующего электрофореза в полиакриламидном геле были изучены белки семян 11 сортов люпина узколистного и родительских форм некоторых из этих сортов. Поскольку белки из семян выделяли экстрагированием трис-глициновым электродным буфером $(\mathrm{pH} \mathrm{8,3)} \mathrm{и} \mathrm{до-}$ полнительную очистку хроматографией или любым иным способом не проводили, то авторы выявили гетерогенность и полиморфизм не только $\alpha-$ и $\beta$-конглютинов, но и некоторых других белков, имеющих схожие физико-химические свойства и потому экстрагирующихся одновременно с запасными белками семян растений (рис. 3, 4). При этом полиморфизм по изучаемым белкам семян был обнаружен не для всех сортов, и для уточнения данных белкового анализа авторы использовали микросателлитный анализ ДНК, позволивший показать полиморфизм у сортов, для которых электрофоретический анализ исследуемых белков семян не дал положительного результата. Авторы заключают, что при отборе родоначальных растений проведение электрофоретического анализа белков каждого из них позволит исключить засорение однородных сортов и сохранить состав и соотношение биотипов у многокомпонентных сортов (44). Однако, как известно, полностью однородных сортов на сегодняшний день практически нет, а используемые в сельском хозяйстве сорта-популяции довольно гетерогенны. То же касается образцов генетических ресурсов растений, сохраняемых в генных банках, или исходному селекционному материалу. Тем не менее электрофорез запасных белков семян растений по-прежнему остается простым и надежным методом контроля чистоты партий 
семенного материала и сохранности товарного знака, то есть установления преимущественно механического загрязнения лотов семян, что в качестве задачи декларирует, например, ISTA (http://www.seedtest.org/en/home.html). В то же время глобальная международная организация Bioversity International (Италия) (http://www.bioversityinternational.org), которая занимается изучением генетического разнообразия, с середины 1990-х годов рекомендует проводить генетический анализ с помощью молекулярных ДНК маркеров $(45,46)$.

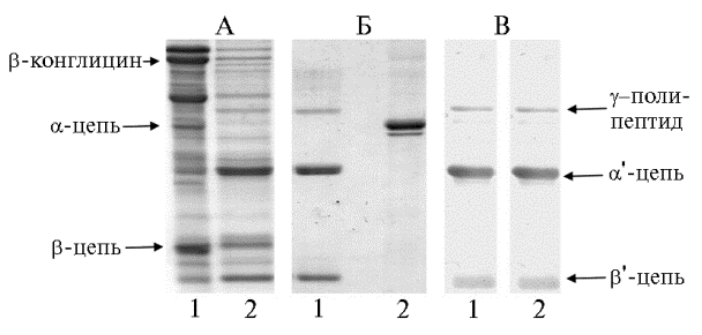

Рис. 3. Выделение и очистка легуминоподобного белка (ЛПБ) из семян сои.

Частичная очистка ЛПБ высаливанием сульфатом аммония (А): 1 - суммарный солевой экстракт, 2 - частично очищенный препарат ЛПБ (фракция при концентрации сульфата аммония 30 \% насыщения).

Препарат ЛПБ, очищенный хроматографической фильтрацией через Qсефарозу (Б): 1 и 2 - электрофореграммы

белка, диссоциированного додецилсульфатом натрия соответственно в присутствии и в отсутствие 2-меркаптоэтанола.

Иммуноблоттинг препарата ЛПБ, частично очищенного высаливанием, против антисыворотки к глицинину сои (В): 1 и 2 - разбавление антисыворотки соответственно в 4000 и 8000 раз; аналогичные результаты получены при использовании антисывороток к $11 \mathrm{~S}$ глобулинам семян кормовых бобов и овса (47).

Результаты, схожие с данными Е.Е. Eggi с соавт. (44), были получены в 1969-1970 и 2006-2007 годах двумя независимыми группами ученых в России в экспериментах по установлению влияния азотного питания на компонентный состав глиадина у озимой пшеницы $(17,48,49)$. Обращает на себя внимание тот факт, что проламины злаков, к которым относится глиадин пшеницы, обладают достаточно широким полиморфным компонентным составом и, как правило, принадлежат к мультигенным семействам, что выгодно отличает их от глобулинов двудольных растений. Однако компонентный состав проламинов, как и любого другого белка семян растений, может быть подвержен изменениям из-за влияния окружающей среды и условий выращивания (см. рис. 1), что и было наглядно продемонстрировано исследованиями российских ученых (17, 48, 49). Пшеницу выращивали в полевых условиях при различных нормах высева, а также при различных дозах минеральных удобрений и пестицидов. Существенные изменения в компонентном составе глиадина наблюдали при внесении повышенных доз азота $(17,48,49)$. Молекулярно-генетический анализ позволил установить, что различные генетически детерминированные компоненты в электрофоретическом спектре глиадинов пшеницы неодинаково реагируют на изменение условий окружающей среды (49). До $30 \%$ компонентов проявляли очень высокую зависимость синтеза от условий выращивания растений. Вполне вероятно, что количественные изменения в синтезе этих белков определяются степенью стабильности соответствующих мРНК (17).

Справедливости ради необходимо отметить, что принципиально любой растительный белок может быть использован в качестве генетического маркера для описания внутривидового полиморфизма с помощью SDS-PAGE, если этот белок удовлетворяет следующим формализованным требованиям: он достаточно консервативен, чтобы его можно было идентифицировать как члена семейства растительных белков, но достаточно 
вариабелен, чтобы его микроэволюционные изменения могли быть обнаружены методом SDS-PAGE; геном в идеале должен содержать либо единственный ген потенциального белка-маркера, либо небольшое число его четко различимых вариантов, сформированных в ходе макроэволюции.

Специально следует оговорить, что необходимым условием применимости метода SDS-PAGE для описания полиморфизма любых белков служит чистота исследуемых препаратов (рис. 4). Неочищенные или грубо очищенные препараты содержат, как правило, полипептиды белковых примесей, близких по молекулярным массам к исследуемым белкам, например к запасным белкам семян растений (см. рис. 4), что усугубляет сложность идентификации их макро- и микроэволюционных вариантов.

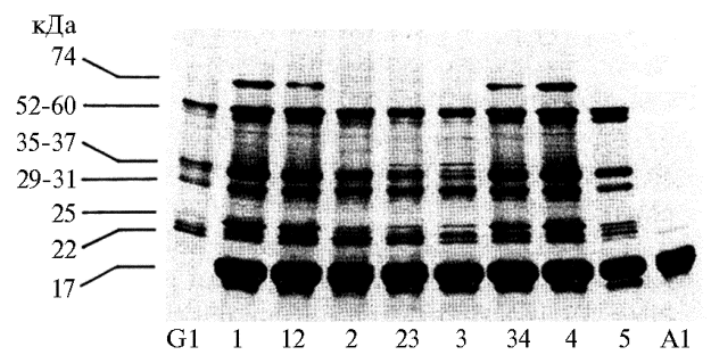

\begin{abstract}
Рис. 4. Денатурирующий электрофорез в полиакриламидном геле (SDS-PAGE) не очищенных хроматографией солерастворимых белков семян: 1 - цветная капуста (Brassica oleraceae), 2 - рапс (B. napus), 3 - турнепс (B. rapa), 4 цветная капуста (B. oleraceae), 5 - кормовая капуста (B. oleraceae); 12, 23 и 34 - смеси соответствующих образцов, Gl и $\mathrm{Al}$ - соответственно очищенные хроматографией $12 \mathrm{~S}$ глобулин и альбумин семян рапса (40).
\end{abstract}

Грубое фракционирование (осаждение и переосаждение) различного рода солями дает лишь предварительную очистку (поскольку вместе с изучаемыми белками всегда выделяются другие белки, содержащиеся в тканях растений и имеющие схожие физико-химические свойства) и служит первым этапом выделения чистого белка, за которым обязательно должен следовать второй этап - очистка хроматографическими или иными методами (рис. 5) (38-40, 50).

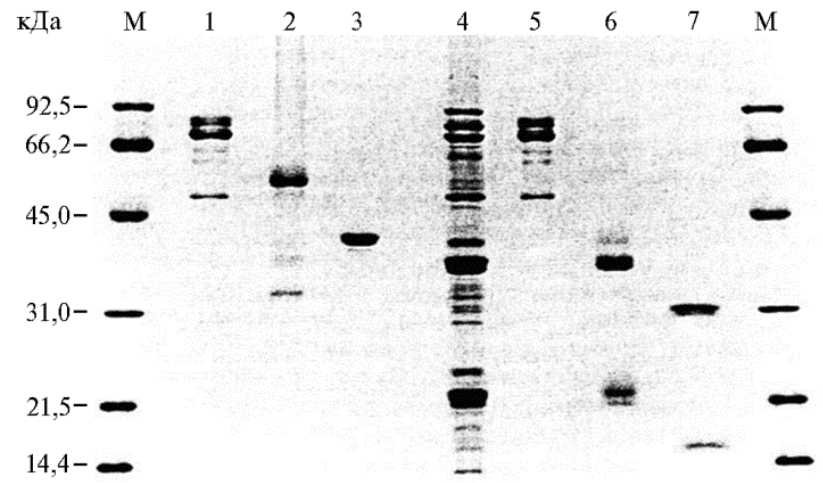

Рис. 5. Анализ запасных белков сои методом SDS-PAGE: 1-3 очищенные белки в отсутствие 2-меркаптоэтанола, 4 - неочищенный белок (сырой экстракт), 5-7 - очищенные белки в присутствии 2-меркаптоэтанола; 1 и $5-7 \mathrm{~S}$ конглицинин; 2 и $6-$ $11 \mathrm{~S}$ глицинин; 3 и $7-8 \mathrm{~S}$ основный глобулин; M - молекулярный маркер (51).

Если очистка хроматографией или иным способом не проводится, то строго необходимо представлять доказательства того, что анализируемый препарат не содержит примесей других белков, либо указывать на гетерогенность анализируемого белкового экстракта. Кроме того, не стоит забывать, что вариабельность электрофоретического спектра грубого экстракта белков при одномерном электрофорезе может быть результатом взаимодействия генотип-среда $(17,34,37,52,53)$, разной степени выполненности зерен (54) и изменения регуляции генной активности $(36,49)$. Дополнительно следует отметить, что разрешающая способность и специфичность методов биоинформатики, применяемых для описания полиморфизма белков на уровне кодирующей нуклеотидной и аминокислотной 
последовательностей, неизмеримо выше по сравнению с любым электрофоретическим методом их анализа $(41,55-57)$, что тоже свидетельствует не в пользу метода SDS-PAGE. И, наконец, с помощью изоферментного анализа обычно выявляется небольшая степень изменчивости, максимум по 20-50 ферментами, визуализируемым с помощью биохимического окрашивания (24), а общий белкового полиморфизма, как правило, зависит от целого ряда факторов эндогенного и экзогенного характера, что обсуждалось выше, и охватывает лишь экспрессируемую часть генома. В ряде случаев показано, что изоферменты различаются по одному или нескольким физиологическим свойствам (58), в связи с чем они не могут быть эволюционно нейтральными.

Более практический аспект заключается в том, что растительные ткани, предназначенные для анализа изоферментов или других белков, должны быть фактически немедленно после сбора использованы для экстракции этих компонентов, поскольку изоферменты, как и другие белки, в таких образцах обычно не слишком стабильны.

Итак, существует целый ряд ограничений, не позволяющих изоферментному, как, впрочем, и любому другому белковому анализу стать универсальным при выявлении генетической изменчивости, несмотря на простоту и низкую себестоимость. Новый аллель может быть обнаружен как полиморфный только в том случае, если замена нуклеотида в ДНК приведет к замене аминокислоты в белке, что, в свою очередь, повлечет изменения в электрофоретической подвижности изучаемых белковых молекул. Генетический код вырожден, и не каждая замена аминокислоты приводит к изменению заряда и существенному изменению молекулярной массы белка, поэтому только 30 \% всех нуклеотидных замен проявляются как детектируемый электрофорезом белковый полиморфизм. Электрофоретический спектр белков зависит от эколого-генетического взаимодействия генотип-среда (например, от изменения условий питания в период биосинтеза белков, воздействия различного рода стрессов, от года, места и времени выращивания растений и т.п.) и даже от условий экстракции белков и проведения электрофореза. Как следствие, с помощью анализа алло-, изоферментов и/или каких-либо других белков невозможно полностью установить и оценить генетическую изменчивость. Еще одна проблема состоит в том, что многие виды растений полиплоидны, а, как известно, у полиплоидных видов анализ изоферментов может быть существенно затруднен. К тому же изоферменты могут различаться по одному или нескольким физиологическим свойствам и в этом случае не могут быть эволюционно нейтральными. Образцы, отобранные для исследования полиморфизма белков, нужно быстро использовать для их выделения и фракционирования. Наоборот, методы, основанные на анализе ДНК, позволяют проводить исследования спустя длительное время после сбора растительных тканей или выделения ДНК благодаря возможности долгосрочного хранения образцов и препаратов без потери свойств. Если сбор растительного материала производится на значительном расстоянии от лаборатории, предпочтительность анализа ДНК особенно очевидна.

\section{ЛИТЕРАТУРА}

1. Соловьева А.Е., Артемьева А.М. Биохимические исследования восточноазиатских листовых овощных растений рода Brassica L. Труды по прикладной ботанике, генетике и селекции, 1999, 157: 142-148.

2. Соловьева А.Е., Артемьева А.М. Капустные растения рода Brassica L. (Характеристика 
образцов по основным биохимическим показателям качества). Каталог мировой коллекции ВИР. СПб, 2004, Вып. 756.

3. Соловьева А.Е., Артемьева А.М. Биологически активные вещества капустных растений рода Brassica L. Аграрная Россия, 2006, 6: 52-56.

4. Соловьева А.Е., Артемьева А.М. Особенности биохимического состава гибридов листовых овощных культур вида Brassica rapa L. Аграрная Россия, 2010, 3: 17-20.

5. Бочарникова Н.И. Генетическая коллекция мутантных форм томата и ее использование в селекционно-генетических исследованиях. М., 2011.

6. Жученко А.А., Король А.Б. Рекомбинация в эволюции и селекции. М., 1985.

7. Жученко А.А., Кибенко Т.Я., Харитон А.М. Влияние температуры среды на электрофоретические спектры белков растений рода Lycopersicon. Tез. докладов конференции «Aдаnтация и рекомбиногенез у культурных растений». Кишинев, 1982: 113.

8. McDonald J.F., Ayala F.J. Gene regulation in adaptive evolution. Canadian Journal of Genetics and Cytology, 1978, 20(2): 159-175.

9. Ayala F.J., McDonald J.F. Continuous variation: possible role of regulatory genes. Genetica, 1980, 52/53: 1-15 (doi: 10.1007/BF00121808).

10. Жученко А.А., Кибенко Т.Я., Харитон А.М., Король А.Б. Оценка скорости изменения спектра легкорастворимых белков диких и культурных форм томата при стрессовых воздействиях. Физиология и биохимия культурных растений, 1984, 16(4): 376-380.

11. Конарев А.В. Адаптивный характер молекулярного полиморфизма и его использование в решении проблем генетических ресурсов растений и селекции. Аграрная Россия, 2002, 3: 4-11.

12. Garvin D.F., Brown A.H.D., Raman H., Read B.J. Genetic mapping of the barley Rrs 14 scald resistance gene with RFLP, isozyme and seed storage protein markers. Plant Breeding, 2000, 119: 193-196 (doi: 10.1046/j. 1439-0523.2000.00456.x).

13. Bahrman N., Damerval C. Linkage relationships of loci controlling protein amount in maritime pine (Pinus pinaster Ait.). Heredity, 1989, 63: 267-274 (doi: 10.1038/hdy.1989.99).

14. Gerber S., Rodolphe F., Bahrman N., Baradat P.H. Seed-protein variation in maritime pine (Pinus pinaster Ait.) revealed by two-dimensional electrophoresis: genetic determination and construction of a linkage map. Theoretical and Applied Genetics, 1993, 85: 521-528 (doi: 10.1007/BF00220908).

15. Plomion C., Bahrman D., Durel C.E., O’Malley D.M. Genomic mapping in Pinus pinaster (maritime pine) using RAPD and protein markers. Heredity, 1995, 74: 661-668 (doi: 10.1038/hdy.1995.90).

16. Plomion C., O’Malley D.M., Durel C.E. Genomic analysis in maritime pine (Pinus pinaster). Comparison of two rapid maps using selfed and open-pollinated seeds of the same individual. Theoretical and Applied Genetics, 1995, 90: 1028-1034 (doi: 10.1007/BF00222917).

17. Плотников В.К. Биология РНК зерновых культур. Краснодар, 2009.

18. Чесноков Ю.В. Молекулярные маркеры и их использование в пребридинговых исследованиях. СПб, 2013.

19. May B. Starch gel electrophoresis of allozymes. In: Molecular genetic analysis of populations: a practical approach /A.R. Hoelzel (ed.). IRL Press, Oxford, 1992: 1-27.

20. Lewontin R.C., Hubby J.L. A molecular approach to study of genetic heterozygosity in natural populations. II. Amount of variation and degree of heterozygosity in natural populations of Drosophila pseudoobscura. Genetics, 1966, 54: 595-609.

21. Murphy R.W., Sites J.W. Jr., Buth D.G., Haufler C.H. Proteins I: isozyme electrophoresis. In: Molecular systematics /D.M. Hillis, C. Moritz (eds.). Sinauer Associates, Sunderland, MA, 1990: 45-126.

22. Tanksley S.D., Rick C.M. Isozymic gene linkage map of the tomato: application in genetics and breeding. Theoretical and Applied Genetics, 1980, 57: 161-170 (doi: 10.1007/BF00279708).

23. Bernatzky R., Tanksley S.D. Toward a saturated linkage map in tomato based on isozymes and random cDNA sequences. Genetics, 1986, 112: 887-898.

24. Tanksley S.D. Molecular markers in plant breeding. Plant Molecular Biology Reporter, 1983, 1: 3-8 (doi: 10.1007/BF02680255).

25. Tanksley S.D., Jones R.A. Application of alcohol dehydrogenase allozymes in testing the purity of $F_{1}$ hybrids of tomato. HortScience, 1979, 16(2): 179-181.

26. Rick C.M., DeVerna J.W., Chetelat R.T., Stevens M.A. Meiosis in sesquidiploid hybrids of Lycopersicon esculentum and Solanum lycopersicoides. PNAS USA, 1986, 83: 3580-3583 (doi: 10.1073/pnas.83.11.3580).

27. Zamir D., Tanksley S.D., Jones R.A. Haploid selection for low temperature tolerance of tomato pollen. Genetics, 1982, 101: 129-137.

28. Zamir D., Tanksley S.D., Jones R.A. Genetic analysis of the origin of plants regeneration from anther tissues of Lycopesicon esculentum Mill. Plant Science Letters, 1981, 21: 223-227 (doi: 10.1016/0304-4211(81)90092-4).

29. Pogson G.H., Mesa K.A., Boutilier R.G. Genetic population structure and gene flow in the 
Atlantic cod Cadus morhua: a comparison of allozyme and nuclear RFLP loci. Genetics, 1995, 139(1): 375-385.

30. Charcosset A., Gallais A. Application of markers in selection. In: Molecular markers in plant genetics and biotechnology /D. De Vienne (ed.). Science Publishers, Inc. Enfield, NH, 2003: 153-176.

31. Vallejos C.E. Enzyme activity staining. In: Isozymes in plant genetics and breeding /S.D. Tanksley, T.J. Orton (eds.). Elsevier, Amsterdam, 1983: 37-49.

32. Shewry P., Franklin J., Parmar S., Smith S.J., Miflin B.J. The effects of sulphur starvation on amino acid and protein compositions of barley grain. Journal of Cereal Science, 1983, 1: 21-31 (doi: 10.1016/S0733-5210(83)80005-8).

33. Spencer D., Rerie W.G., Randall P.J., Higgins T.J.V. The regulation of pea seed storage protein genes by sulphur stress. Australian Journal of Plant Physiology, 1990, 17: 355-363 (doi: 10.1071/PP9900355).

34. Chiaese P., Ohkama-Ohtsu N., Molvig L., Godfree R., Dove H., Hocart C., Fujiwara T., Higgins T.J., Tabe L.M. Sulphur and nitrogen nutrition influence the response of chickpea seeds to an added, transgenic sink for organic sulphur. Journal of Experimental Botany, 2004, 55: 18891901 (doi: 10.1093/jxb/erh198).

35. Sharma A., Sharma S. Effect of nitrogen and sulphur nutrition on storage protein quality in soybean [Glycine max (L.) Merrill]. Journal of Applied and Natural Science, 2018, 10(1): 296300 (doi: 10.31018/jans.v10i1.1620).

36. Shewry P., Casey R. Seed proteins. In: Seed proteins /P. Shewry, R. Casey (eds.). Kluwer Acad. Publishers, Dordrecht, London, 1999: 1-10.

37. Tabe L., Hagan N., Higgins T.J.V. Plastisity of seed protein composition in response to nitrogen and sulphur availability. Current Opinion in Plant Biology, 2002, 5: 212-217 (doi: 10.1016/S1369-5266(02)00252-2).

38. Crouch M., Sussex I.M. Development and storage-protein synthesis in Brassica napus L. embryos in vivo and in vitro. Planta, 1981, 153: 64-74 (doi: 10.1007/BF00385319).

39. Shwenke K.D., Raab B., Plietz P., Damaschun G. The structure of the $12 \mathrm{~S}$ globulin from rapeseed (Brassica napus L.). Die Nahrung, 1983, 27: 165-175 (doi: 10.1002/food.19830270208).

40. Mimouni B., Robin J.-M., Azanza J.-L. Comparative studies of $11 \mathrm{~S}$ globulin constituents of Brassica napus L. and of its related species Brassica campestris L. and Brassica oleracea L. Plant Science, 1990, 67: 183-194 (doi: 10.1016/0168-9452(90)90242-G).

41. Chesnokov Yu.V., Shutov A.D. 11S seed storage globulins: are they reliable as molecular markers? In: Recent Research Developments in Genetics and Breeding. Research Signpost, Kerala, India, 2004, Vol. 1: 181-194.

42. International Rules for Seed Testing. Rules 1996. Verification of species and cultivars. Seed Science Technology, 1996, 24(Suppl.): 253-270.

43. Теоретические основы селекции. T. 1. Молекулярно-биологические аспекты прикладной ботаники, генетики и селекции /Под ред. В.Г. Конарева. М., 1993.

44. Егги Э.Э., Вишневская М.С., Агеева П.А., Мехтиев В.С., Гаврилюк И.П., Гапонов Н.В., Красильников В.Н. Использование полиморфизма белков семян для сортовой идентификации люпина узколистного (Lupinus angustifolius L.). Аграрная Россия, 2012, 4: 2-8.

45. Karp A., Kresovich S., Bhat K.V., Ayad W.G., Hodgkin T. Molecular tools in plant genetic resources conservation: a guide to the technologies. IPGRI Technical Bulletin, No. 2. International Plant Genetic Resources Institute, Rome, Italy, 1997.

46. Spooner D., Van Treuren R., De Vicente M.C. Molecular marker for gene bank management. IPGRI Technical Bulletin, No. 10. International Plant Genetic Resources Institute, Rome, Italy, 2005.

47. Шутов А., Рудаков С., Рудакова А., Сеферова И., Каховская И., Алпатьева Н., Тимофеева Г., Чесноков Ю. Легуминоподобный белок семян сои: очистка и некоторые свойства. Analele Stiintifice ale Universitatii de Stat din Moldova, Seria «Stiinte chimico-biologice». Chisinau, CEP USM, 2006: 240-243.

48. Вертий С.А., Ветрукова А.М., Волкова В.А., Конарев В.Г., Гаврилюк И.П., Хакимова А.Г. Влияние уровня азотного питания на компонентный состав глиадина озимой пшеницы в связи с ее хлебопекарными свойствами. Доклады ВАСХНИЛ, 1972, 4: 8-10.

49. Букреева И.Г., Мельникова Е.Е., Плотников В.К. Количественные изменения в спектре глиадиновых белков зерна пшеницы как результат взаимодействия «генотип-среда». Материалы докладов Международной конференции «Современная физиология растений: от молекул до экосистем». Сыктывкар, 2007, ч. 3: 14-15.

50. Скоупс Р. Методы очистки белков. М., 1985.

51. Autran J.C., Halford N.G., Shewry P.R. The biochemistry and molecular biology of seed storage proteins. In: Plant nitrogen /P.J. Lea, J.F. Morot-Gaudry (eds.). Springer, Berlin, Heidelberg, 2001: 295-341 (doi: 10.1007/978-3-662-04064-5_12).

52. Антошкина М.С., Добруцкая Е.Г., Гинс В.К., Старцев В.И., Фарбер С.П. Методические 
рекомендации по анализу белков семян капустных культур методом электрофореза. М., 2007.

53. Наимов С.Н., Касымова Г.Ф., Донцова С.В., Нигмонов М. Характеристика глиадинов вида Aegilops L., произрастающих в различных почвенно-климатических условиях Таджикистана. Материалы докладов Международной конференции «Современная физиология растений: от молекул до экосистем». Сыктывкар, 2007, ч. 1: 202-203.

54. Ларикова Ю.С. Фракционный состав белков зерновок пшеницы разной степени выполненности. Материалы докладов Международной конференции «Современная физиология растений: от молекул до экосистем». Сыктывкар, 2007, ч. 3: 376-378.

55. Чесноков Ю.В., Шутов А.Д. Запасные $11 \mathrm{~S}$-глобулины семян как альтернатива ДНКмаркерам. Доклады РАСХН, 2006, 3: 7-11.

56. Чесноков Ю.В. Генетические ресурсы растений и современные методы ДНК-типирования. СПб, 2007.

57. Стефанов В.Е., Мавропуло-Столяренко Г.Р. Анализ структуры белков методами биоинформатики. СПб, 2007.

58. Brown A.H.D., Marshall D.R., Munday J. Adaptedness of variants at an alcohol dehydrogenase locus in Bromus mollis L. (soft brome grass). Australian Journal of Biology. Science, 1976, 29: 389-396 (doi: 10.1071/BI9760389).

\author{
ФГБНУ Агрофизический научно-исследовательский \\ институт, \\ 195220 Россия, г. Санкт-Петербург, Гражданский просп., 14, \\ e-mail: yuv_chesnokov@agrophys.ru
}

Поступила в редакцию 9 января 2019 года

Sel’skokhozyaistvennaya biologiya [Agricultural Biology], 2019, V. 54, № 5, pp. 863-874

\title{
BIOCHEMICAL MARKERS IN GENETIC INVESTIGATIONS OF CULTIVATED CROPS: THE PROS AND CONS
}

\author{
(review)
}

\author{
Yu.V. Chesnokov
}

Agrophysical Research Institute, 14, Grazhdanskii prosp., St. Petersburg, 195220 Russia, e-mail yuv_chesnokov@agrophys.ru ORCID:

Chesnokov Yu.V. orcid.org/0000-0002-1134-0292

The author declares no conflict of interests

Received January 9, 2019

doi: 10.15389/agrobiology.2019.5.863eng

\section{Abstract}

This literature review summarizes the accumulated knowledge and the author's own research data about suitability of seed storage proteins, allozymes and isozymes as biochemical genetic markers. These markers have a huge potential, since it allows researchers to distinguish genotypes from other in a short time. Therewith, biochemical markers are usually tissue- and organ-specific. The advantages that these markers possess over morphological markers are shown. So biochemical markers can be used on a much larger number of experimental objects than morphological ones. Protein markers are usually characterized by a greater correspondence between genotype and phenotype, and, besides, the path to the implementation of genetic differences into phenotypic ones for protein markers is much shorter than for morphological ones. In addition, metabolites (sugars, carbohydrates, secondary metabolites, etc.), which are identified biochemically after isolation from the organs or tissues of the studied organism and purification, are also referred to biochemical genetic markers. Though more than half a century has passed since the first description of biochemical markers, the physicochemical bases to their detection and identification have hardly changed methodologically. This gives some limitations on their use in genetic investigations. For example, it is shown, that plant protein polymorphisms revealed by one-dimensional electrophoresis can be subjected to quality and quantity changes because of ecological stresses such as nutrition deficiency or temperature deviations. Researchers also must take into account casual destructive changes and breaks of the analyzed molecules for various reasons, including due to non-standard conditions for protein and polypeptide extraction and purification, as well as during electrophoretic separation, which leads to non-specific electrophoretic spectra. Because of degeneracy of the genetic code and the fact that not every amino acid substitution leads to a change in charge and the molecular weight of the protein, only $30 \%$ of nucleotide substitutions can cause electrophoretically detected protein polymorphism. Only strict observance of all methodological, biological and other restrictions, as well as established requirements, allow the correct and skillful use of biochemical markers in genetic research.

Keywords: seed storage proteins, allozymes, isozymes, polymorphism, electrophoretic patterns, biochemical markers. 